Article

\title{
Improved Self-Supporting and Ceramifiable Properties of Ceramifiable EPDM Composites by Adding Aramid Fiber
}

\author{
Dong Zhao ${ }^{1,2}$, Wei Liu ${ }^{1,2}$, Yucai Shen ${ }^{1,3, *}$, Guodong Jiang ${ }^{1,3}$ and Tingwei Wang 1,3,* \\ 1 College of Material Science and Engineering, Nanjing Tech University, Nanjing 211816, China; \\ 8113557343@njtech.edu.cn (D.Z.); 201861103043@njtech.edu.cn (W.L.); gdjiang@njtech.edu.cn (G.J.) \\ 2 Jiangsu Collaborative Innovation Center for Advanced Inorganic Function Composites, \\ Nanjing 211816, China \\ 3 Suqian Advanced Materials Institute of Nanjing Tech University, Suqian 223800, China \\ * Correspondence: ycshen@njtech.edu.cn (Y.S.); wangtw@njtech.edu.cn (T.W.); \\ Tel.: +86-159-5182-6321 (Y.S.); +86-136-0158-5533 (T.W.)
}

Received: 5 June 2020; Accepted: 7 July 2020; Published: 9 July 2020

\begin{abstract}
Ceramifiable ethylene propylene diene monomer (EPDM) composites with fiber network structures were prepared by using aramid fiber (AF), ammonium polyphosphate (APP), and silicate glass frits (SGF). The effect of AF on the curing characteristic of the ceramifiable EPDM composites was studied. The morphology of AF in the composites system was observed by optical microscopy (OM) and scanning electron microscope (SEM). The effects of the observed AF network structures on the solvent resistance, mechanical properties, ablative resistance, self-supporting property, and ceramifiable properties of the composites were investigated. Results suggested that the existence of the AF network structure improved the vulcanization properties, solvent resistance, thermal stability, and ablative resistance of the EPDM composites. An excellent self-supporting property of the EPDM composites was obtained by combining the formation of the AF network and the formation of crystalline phases at higher temperature (above $600^{\circ} \mathrm{C}$ ). The thermal shrinkage performance of $\mathrm{AF}$ and the increased thermal stability of the EPDM composites improved the ceramifiable properties of the EPDM composites.
\end{abstract}

Keywords: EPDM; ceramifiable; aramid fiber; self-supporting; thermal stability

\section{Introduction}

Polymeric ablative materials are usually used for insulation and fire prevention in electric power and propulsion systems [1-3]. Ethylene-propylene-diene monomer (EPDM) represents one of the best matrices for polymeric ablative materials [4-6]; the thermal stability and electrical insulation of EPDM is comparable to or higher than that of other rubbers [7]. Therefore, EPDM as a synthetic rubber is used in construction, electrical insulation, automobile manufacturing, and even propulsion systems of solid rocket motors [8-11]. However, as a type of thermal protection material, the dripping and bending behaviors of EPDM composites have been the most serious drawback, which can cause the composite to lose its thermal protection function and even ignite other flammable materials. Thus, it is important to develop a novel EPDM composite with self-supporting and anti-dripping properties.

In addition, EPDM composite has been often used in the thermal protection field because of its high char yield, which increases the ablation resistance and the thermal insulation performance $[3,8,10,12]$. With the development of aerospace solid propulsion technology, the thermal protection material will also be mechanically eroded by the action of condensed high speed solid alumina particles produced 
during the combustion of modern aluminized solid rocket motor propellants $[13,14]$. Thus, this requires a thermal protection material with higher anti-erosion and ablation resistance properties.

Ceramifiable polymer composites possess the performance features of polymers at room temperature and of ceramics at high temperatures [15-19]. Bennett and Young [20] reported that for the glass ceramic containing boron, in which $\mathrm{B}_{2} \mathrm{O}_{3}$ can be formed from borates and boric acid at high temperatures, a glassy protective layer emerged. Novel laponite-armored hollow composite particles (LHCPs) with a pre-organized "house-of-cards" structure were synthesized by Zhang [21]. It was revealed that the ceramifiable silicone rubber with laponite platelets as fillers can maintain its shape and mechanical strength in the range of $500-900{ }^{\circ} \mathrm{C}$. The ceramic residues of ceramifiable silicone rubber can also act as a heat transport barrier that protects the underlying material from incoming heat flux [22]. In addition, the fire resistance and ablation resistance of the ceramifiable polymer composites at high temperatures could be further improved by forming crystalline phases. In our previous work $[23,24]$, a novel ceramifiable ethylene-vinyl acetate (EVA) composite and a novel ceramifiable silicon rubber composite were successfully prepared. A novel ceramization mechanism of liquid-solid transition was also proposed. However, the formation of inorganic crystalline phases tends to happen at high temperatures (over $600{ }^{\circ} \mathrm{C}$ ). Before the formation of crystalline phases, polymer composites are often too weak to keep their original shape. A cross-linking modification was often considered to enhance the thermal stability of the composites [25,26], and ceramifiable EVA composites with improved self-supporting and ceramifiable properties were obtained using a cross-linking strategy [27]. However, there are still dripping and bending behaviors during the ablation process for cross-linked ceramifiable EPDM composites.

Aramid fibers (AF) were often used as a low-density reinforcement due to their high thermal capacity, high chemical stability, high fire resistance, and high ablation resistance [28-31]. Qin et al. [32] prepared a type of ceramifiable EPDM rubber composites with EPDM, AF, flux, and other fillers and focused on the investigation of the effect of different fluxes on the formation of ceramic structure. Chen et al. [33] found that AF could improve the ablative resistance of EPDM vulcanizate effectively compared to basalt fiber and carbon fiber. Maurizio et al. [5,34] prepared a type of EPDM thermal protective material for a solid rocket motor. They found that AF had a better interfacial compatibility with the EPDM matrix than silicon fiber. In addition, AF formed a carbon framework at high temperatures, which improved the ablative resistance of the composite. Li et al. [35] studied the ablation and erosion characteristics of EPDM composites under realistic solid rocket motor operating conditions. They found that the combined use of silica and AF in EPDM composites can improve the heat-shielding performance of the char layer. In this work, in order to significantly improve the thermal stability of the ceramifiable EPDM composite before the formation of crystalline phases at high temperature, a novel ceramifiable EPDM composite was prepared by adding AF, ammonium polyphosphate (APP), and silicate glass frits (SGF) as a ceramic precursor. We aimed to improve the self-supporting performance and optimize the ceramifiable properties of EPDM composite by forming an AF network structure.

\section{Experimental}

\subsection{Materials}

Ethylene propylene diene monomer (EPDM) (DuPont, Nordel IP-4725P) and aramid fiber (AF) (ALKEX, AF-1000) were supplied by Shanghai Academy of Aerospace Propulsion Technology. Silicate glass frits (SGF) (500 mesh) was provided by Donggu New Material Co., Ltd. (Foshan, China). Ammonium polyphosphate (APP) (crystalline form II, polymerization degree exceeds 1500) was supplied by Zhengzhou Hao Rong Chemical Products Co., Ltd. (Zhengzhou, China). Sulfur (S) was purchased from Merck, Germany. Dicumyl peroxide (DCP) was supplied by He Fei An Bang Chemical Co., Ltd. (Hefei, China). 


\subsection{Sample Preparation}

EPDM and other materials were compounded on a two-roll mill, as listed in Table 1. The rolls were set to a temperature of $50^{\circ} \mathrm{C}$. EPDM was first mixed with AF, and then the SGF and APP were added. Finally, the remaining additives (DCP and $S$ ) were added. The total mixing time was $15 \mathrm{~min}$. The vulcanization parameters, curing time $\left(t_{90}\right)$, and maximum $\left(M_{\mathrm{H}}\right)$ and minimum $\left(M_{\mathrm{L}}\right)$ torque were determined using the Dynamic Moving Die Rheometer (MDR 2000, Wuxi Liyuan Electronic \& Chemical Equipment Co., Ltd., Wuxi, China). For characterization of the ceramifiable EPDM composites, sheets with thicknesses of 2 and $10 \mathrm{~mm}$ were cured in a compression mold at a temperature of $180{ }^{\circ} \mathrm{C}$ with a pressure of $10 \mathrm{MPa}$ for $15 \mathrm{~min}$.

Table 1. Formulations of ceramifiable EPDM composites (g).

\begin{tabular}{ccccccc}
\hline Sample & EPDM & SGF & APP & AF & DCP & S \\
\hline EPDM/AF & 70 & 85 & 45 & 0 & 2.10 & 0.35 \\
EPDM/AF $_{5}$ & 70 & 85 & 45 & 3.5 & 2.10 & 0.35 \\
EPDM/AF $_{10}$ & 70 & 85 & 45 & 7 & 2.10 & 0.35 \\
EPDM/AF $_{15}$ & 70 & 85 & 45 & 10.5 & 2.10 & 0.35 \\
\hline
\end{tabular}

\subsection{Characterization}

The microstructure of the cured ceramifiable EPDM composites and the distribution of the AF in the system were observed using a metallographic microscope (Axio Observer A1m, Carl Zeiss Jena Company, Jena, Germany).

Samples with the dimensions of $20 \mathrm{~mm} \times 20 \mathrm{~mm} \times 2 \mathrm{~mm}$ were immersed in $40 \mathrm{~mL}$ of tetrachloromethane solution at $25^{\circ} \mathrm{C}$ for $12 \mathrm{~h}$. The liquid absorbency (A) was calculated as follows with Equation (1):

$$
A=\left(m_{\mathrm{t}}-m_{0}\right) / m_{0} \times 100 \%
$$

where $A$ is the liquid absorbency, and $m_{0}$ and $m_{\mathrm{t}}$ are the weight of the dry sample and swollen sample, respectively. In addition, the dimension of the sample before and after swelling was also recorded.

Tear tests were carried out using a universal testing machine (CMT 5254, Shenzhen SANS Testing Machine Co., Ltd., Shenzhen, China), under a stable rate of $100 \mathrm{~mm} / \mathrm{min}$, according to the GB/T529-2008 standard. The test results were the average of at least five specimens.

All samples $(125 \mathrm{~mm} \times 13 \mathrm{~mm} \times 2 \mathrm{~mm})$ were measured using the vertical burning test instrument (CZF-3) (Nanjing Jiangning analytical instrument factory, Nanjing, China) according to the GB/T10707-2008 standard.

The self-supporting property of the ceramifiable EPDM composites was tested by measuring the bending angles of the composites after firing at different temperatures for $30 \mathrm{~min}$ in a muffle furnace. The test method is as follows: (1) firstly, the sample ( $50 \mathrm{~mm} \times 5 \mathrm{~mm} \times 2 \mathrm{~mm})$ was placed on a refractory brick. Moreover, the long axis of the sample was perpendicular to the edge of the brick, and $20 \%$ of the length of the sample extended from the edge of the brick; (2) then, all samples were fired at 600, 700, 800, and $900{ }^{\circ} \mathrm{C}$; (3) finally, the bending angle of the residue to its original position was obtained [24].

The linear ablation rate test under a oxyacetylene torch was conducted following the GJB323A-96 standard. All specimens were vertically subjected to the flame gun with a heat flux of $4110.0 \mathrm{KW} / \mathrm{m}^{2}$. Gas pressures of $\mathrm{O}_{2}$ and $\mathrm{C}_{2} \mathrm{H}_{2}$ were 0.4 and $0.095 \mathrm{MPa}$, respectively, and the gas fluxes were 1512 and $1116 \mathrm{~L} / \mathrm{h}$, respectively. The oxyacetylene gun tip was $2 \mathrm{~mm}$ in diameter, and its distance from the sample was $10 \mathrm{~cm}$. Linear ablation rates of the specimens were obtained according to Equation (2):

$$
A=\left(d_{\mathrm{t}}-d_{0}\right) / t
$$

where $A$ is the linear ablation rate; $d_{\mathrm{t}}$ and $d_{0}$ are the thickness of the specimen at the center region before and after ablation, respectively; and $t$ is the ablation time. Three specimens were tested for each of the samples. 
The flexural strength of residues was tested on a universal testing machine (UH 6502, Youhong Measurement and Control Technology Co., Ltd., Shanghai, China) by the three-point bend method at a stable rate of $0.5 \mathrm{~mm} / \mathrm{min}$, according to the GB/T9596-2006 standard.

Linear shrinkage was obtained according to the length of the sample before and after firing at high temperatures. The linear shrinkage was calculated using Equation (3):

$$
L=\left(L_{0}-L_{\mathrm{d}}\right) / L_{0} \times 100 \%
$$

where $L$ is linear shrinkage (\%); and $L_{0}$ and $L_{\mathrm{d}}$ are the length of the specimen before and after firing, respectively.

Thermogravimetric analysis (TGA) was performed on a TA Instruments (STA449C) at a heating rate of $10^{\circ} \mathrm{C} / \mathrm{min}$ under $\mathrm{N}_{2}$ atmosphere. All composites were heated in a temperature range from room temperature to $800^{\circ} \mathrm{C}$. Moreover, pure AF was heated from room temperature to $700{ }^{\circ} \mathrm{C}$.

The surface morphology of the residue and the state of AF in the residue were observed on a scanning electron microscope (SEM) (JSM-6510, Jeol, Tokyo, Japan) with an acceleration voltage of $15 \mathrm{kV}$.

The phase composition of the residue powders were characterized through an X-ray diffraction instrument (Rigaku Corporation, Akishima, Tokyo, Japan) with $\mathrm{Cu} \mathrm{K} \alpha$ radiation in the $2 \theta$ range of $10^{\circ}-80^{\circ}$ at a scan rate of $10^{\circ} / \mathrm{min}$.

The fourier transform infrared spectroscopy (FTIR) spectra of residue powders were recorded with a Nicolet spectrometer (NEXUS670, Thermo Fisher, Waltham, MA, USA) with a range of $4000-400 \mathrm{~cm}^{-1}$.

\section{Results and Discussion}

\subsection{Curing Properties of Ceramifiable EPDM Composites}

The vulcanization properties of pure EPMD at different temperatures are shown in Figure 1a and Table 2. It was observed that ceramifiable EPDM has a different optimum cure time at different temperatures. Under the curing time of $900 \mathrm{~s}$, EPDM was not in the plateau of vulcanizing curves at 160 and $170{ }^{\circ} \mathrm{C}$, while the state of vulcanized EPDM was in the plateau of vulcanizing curves at the temperature of $180{ }^{\circ} \mathrm{C}$. Therefore, the curing condition of $180^{\circ} \mathrm{C}$ and $900 \mathrm{~s}$ was applied for ceramifiable EPDM composites. Figure $2 b$ and Table 3 show the curing properties of the ceramifiable EPDM composites. The addition of inorganic fillers (SGF and APP) and AF into the EPDM rubber increased its minimum torque $\left(M_{\mathrm{L}}\right)$ and maximum torque $\left(M_{\mathrm{H}}\right)$, which can be ascribed to the inorganic reinforcing fillers [36,37]. Table 3 shows that the $M_{\mathrm{H}}$ value gradually increased with further addition of AF, showing again the reinforcing effect of AF. The value of $\Delta M\left(M_{\mathrm{H}}-M_{\mathrm{L}}\right)$ increased as the content of AF increased, indicating that reduced slippage between the polymer chains may occur [38].
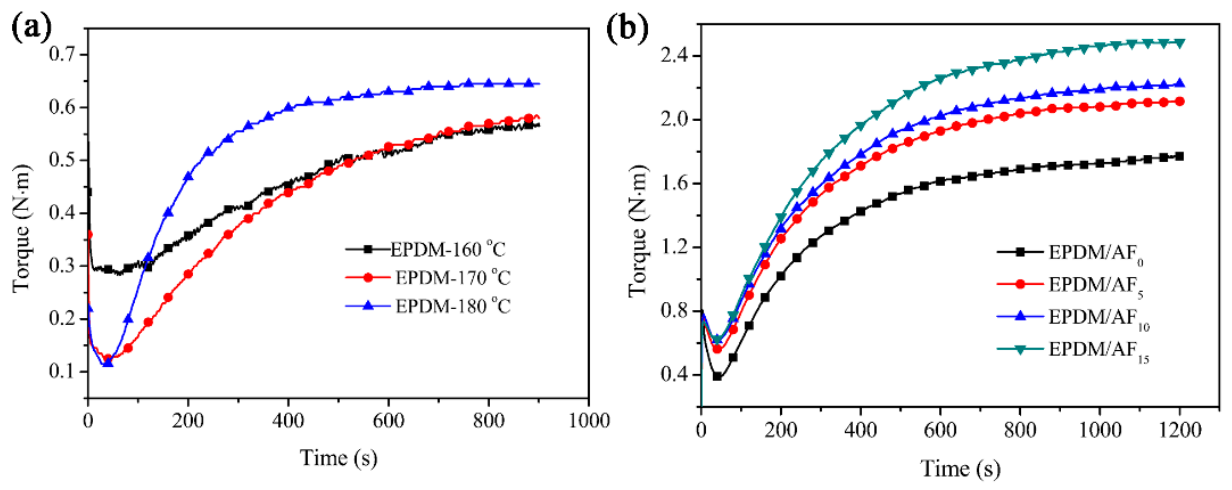

Figure 1. Curing curves of the pure EPDM (a) and ceramifiable EPDM composite (b). 
Table 2. Curing characteristics of pure EPDM at different temperatures.

\begin{tabular}{cccccc}
\hline Sample & $\boldsymbol{t}_{\mathbf{1 0}}(\mathbf{s})$ & $\boldsymbol{t}_{\mathbf{9 0}}(\mathbf{s})$ & $\boldsymbol{M}_{\mathbf{L} /}(\mathbf{N} \cdot \mathbf{m})$ & $\boldsymbol{M}_{\mathbf{H} /}(\mathbf{N} \cdot \mathbf{m})$ & $\boldsymbol{\Delta} \boldsymbol{M} / \mathbf{( N \cdot m )}$ \\
\hline EPDM-160 ${ }^{\circ} \mathrm{C}$ & 127 & 689 & 0.28 & 0.57 & 0.29 \\
EPDM-170 ${ }^{\circ} \mathrm{C}$ & 102 & 651 & 0.12 & 0.59 & 0.47 \\
EPDM-180 ${ }^{\circ} \mathrm{C}$ & 70 & 388 & 0.11 & 0.65 & 0.53 \\
\hline
\end{tabular}

Table 3. Curing characteristics of ceramifiable EPDM composites at $180^{\circ} \mathrm{C}$.

\begin{tabular}{cccccc}
\hline Sample & $\boldsymbol{t}_{\mathbf{1 0}}(\mathbf{s})$ & $\boldsymbol{t}_{\mathbf{9 0}}(\mathbf{s})$ & $\boldsymbol{M}_{\mathbf{L} /}(\mathbf{N} \cdot \mathbf{m})$ & $\boldsymbol{M}_{\mathbf{H} /}(\mathbf{N} \cdot \mathbf{m})$ & $\boldsymbol{\Delta} \boldsymbol{M} / \mathbf{( N \cdot m )}$ \\
\hline${\text { EPDM} / A_{0}}$ & 84 & 559 & 0.39 & 1.72 & 1.33 \\
${\text { EPDM } / A_{5}}$ & 86 & 586 & 0.56 & 2.07 & 1.51 \\
EPDM $_{10} \mathrm{AF}_{15}$ & 86 & 650 & 0.62 & 2.23 & 1.61 \\
\hline
\end{tabular}

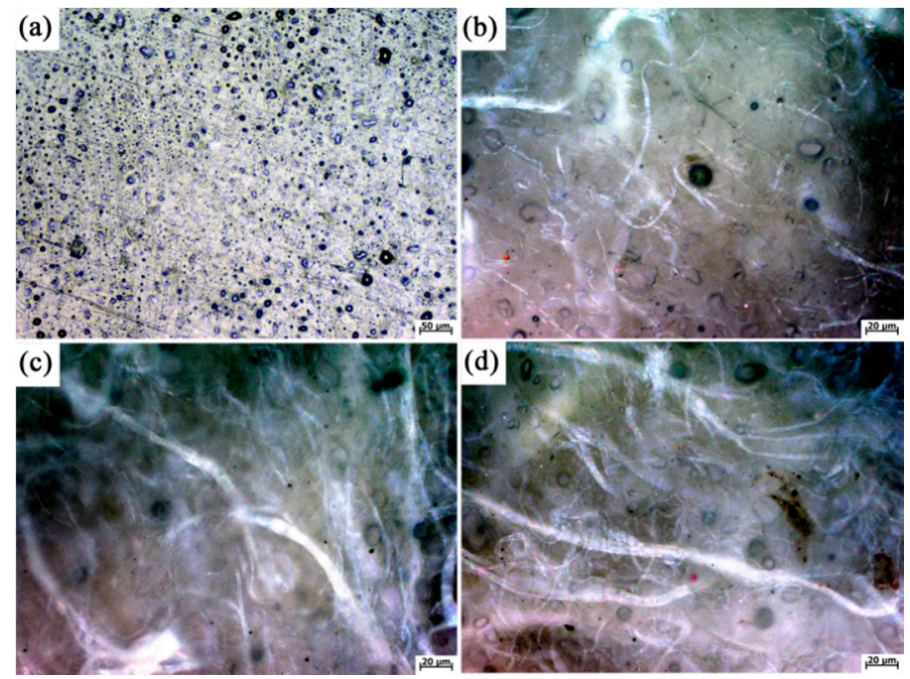

Figure 2. Optical microscopy $(\mathrm{OM})$ photographs of $\mathrm{EPDM} / \mathrm{AF}_{0}(\mathbf{a}), \mathrm{EPDM} / \mathrm{AF}_{5}(\mathbf{b}), \mathrm{EPDM} / \mathrm{AF}_{10}$ (c), and $\mathrm{EPDM} / \mathrm{AF}_{15}(\mathbf{d})$.

\subsection{Surface Morphology of Ceramifiable EPDM Composites}

In order to observe the effect of AF on the ceramifiable EPDM composites, the morphology of the ceramifiable EPDM composites for various contents of AF were characterized using optical microscopy $(\mathrm{OM})$ (Figure 2). The OM micrographs of the surface of $\mathrm{EPDM} / \mathrm{AF}_{10}$ and $\mathrm{EPDM} / \mathrm{AF}_{15}$ indicate that the AF was evenly distributed. There were many superfine fibers sticking on the main trunk fiber, which could promote the formation of a fiber network in ceramifiable EPDM composites.

\subsection{Swelling Property of Ceramifiable EPDM Composites}

The swelling test results of the ceramifiable EPDM composites are presented in Figure 3 and Table 4. It is clear that the sample of $\mathrm{EPDM} / \mathrm{AF}_{0}$ showed the most serious dimensional changes and the highest liquid absorbency among all the composites. In tetrachloromethane solvent, the percentage of liquid absorbency significantly decreases with increasing AF content from 5-15 wt \%. It can be observed that there was little change in the dimension of sample EPDM/AF 15 , as shown in Figure 3. It is widely accepted that the swelling is directly related to the cross-linking density of molecular chains [39-41], and less solvent uptake or penetration into the blends indicated higher cross-linking density. However, there is no cross-linking reaction between EPDM molecular chains and AF fiber; the lower solvent uptake or penetration into the blends could be attributed to the AF fiber, which restricted the slippage between the polymer chains [41]. Therefore, the solvent cannot easily penetrate into 
the blends. Swelling test results showed that the addition of AF enhanced the interaction within the system of the composite. This enhanced interaction within the system of the material might be able to improve the self-supporting and anti-dripping properties at high temperatures.
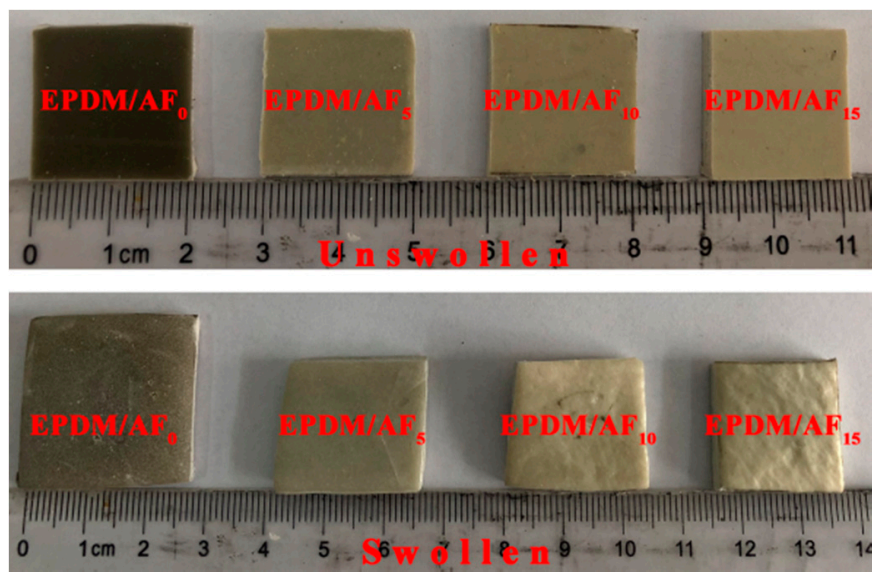

Figure 3. Digital photos of ceramifiable EPDM composite before and after swelling in pure tetrachloromethane.

Table 4. Liquid absorbency and dimensional change of ceramifiable EPDM composites in pure tetrachloromethane.

\begin{tabular}{|c|c|c|c|}
\hline \multicolumn{2}{|c|}{ Sample } & \multirow{3}{*}{$\begin{array}{c}\text { Dimensional Change (Length } \times \text { Width) }(\mathrm{mm}) \\
20.08 \times 20.06 \\
29.34 \times 29.34\end{array}$} & \multirow{3}{*}{$\frac{\text { Liquid Absorbency (\%) }}{252.23}$} \\
\hline & Before swelling & & \\
\hline EPDM/AF 0 & After swelling & & \\
\hline \multirow{2}{*}{$\mathrm{EPDM} / \mathrm{AF}_{5}$} & Before swelling & $20.08 \times 20.18$ & \multirow{2}{*}{184.25} \\
\hline & After swelling & $21.24 \times 24.50$ & \\
\hline \multirow{2}{*}{$\mathrm{EPDM} / \mathrm{AF}_{10}$} & Before swelling & $20.04 \times 20.14$ & \multirow{2}{*}{150.72} \\
\hline & After swelling & $21.10 \times 23.20$ & \\
\hline \multirow{2}{*}{$\mathrm{EPDM} / \mathrm{AF}_{15}$} & Before swelling & $20.02 \times 20.04$ & \multirow{2}{*}{132.66} \\
\hline & After swelling & $20.90 \times 20.90$ & \\
\hline
\end{tabular}

\subsection{Mechanical Properties of Ceramifiable EPDM Composites}

Table 5 shows that there was an obvious increase in tear strength from $14.85 \mathrm{~N} / \mathrm{m}$ to $22.02 \mathrm{~N} / \mathrm{m}$ for ceramifiable EPDM composites when the content of AF increases from 5 to $15 \mathrm{wt} \%$. The improvement of tear strength was due to the addition of AF for absorbing energy and blocking crack-growth during the tearing process [42].

Table 5. Mechanical properties of ceramifiable EPDM composites.

\begin{tabular}{cc}
\hline Sample & Tearing Strength $(\mathbf{N} / \mathbf{m})$ \\
\hline EPDM$/ A F_{0}$ & $11.53 \pm 0.62$ \\
EPDM/AF $_{5}$ & $14.85 \pm 0.70$ \\
EPDM/AF $_{10}$ & $16.61 \pm 0.95$ \\
${\text { EPDM } / A_{15}}$ & $22.02 \pm 0.65$ \\
\hline
\end{tabular}

\subsection{Anti-Dripping and Self-Supporting Properties of Ceramifiable EPDM Composites}

It can be seen from Table 6 that samples $\mathrm{EPDM} / \mathrm{AF}_{0}$ and $\mathrm{EPDM} / \mathrm{AF}_{5}$ had serious melt dripping, while $\mathrm{EPDM} / \mathrm{AF}_{10}$ and $\mathrm{EPDM} / \mathrm{AF}_{15}$ did not show any melt dripping. However, no samples achieved any classification in the UL 94 test, as they did not extinguish within a short time period of the defined specimen after removing the Bunsen-burner-type ignition source. 
Table 6. Combustion test results of ceramifiable EPDM composites.

\begin{tabular}{ccc}
\hline Sample & Dripping or Not & UL94 Rating \\
\hline${\text { EPDM } / \mathrm{AF}_{0}}_{\mathrm{EPDM} / \mathrm{AF}_{5}}$ & Dripping & Dripping \\
$\mathrm{EPDM} \mathrm{AF}_{10}$ & No dripping & NC \\
$\mathrm{EPDM}_{1} \mathrm{AF}_{15}$ & No dripping & NC \\
\hline
\end{tabular}

NC: not classified without self-extinguishing.

To characterize the self-supporting property, the bending angles of ceramifiable EPDM composites firing at high temperatures were tested. As shown in Table 7, when the firing temperature increased from 700 to $900{ }^{\circ} \mathrm{C}$, the bending angles of the residues obtained by firing the same sample increased in different degrees. Under the same firing condition, the bending angles of the sample decreased with the increasing content of AF. The occurrence of bending behavior was ascribed to soften and molten of the materials at high temperatures. Bending deformation of the ceramifiable composites can be suppressed by forming a crystalline phase at high temperatures (above $600{ }^{\circ} \mathrm{C}$ ) [24,27]. Before the formation of the crystalline phase, the polymer composite is often too weak to support its own weight. The addition of AF could significantly enhance the thermal stability of the EPDM composites by forming a fiber network structure, leading to a remarkable improvement of the self-supporting property at high temperatures.

Table 7. Bending angles for the residues of ceramifiable EPDM composites firing at different temperatures.

\begin{tabular}{ccccc}
\hline Sample & $\begin{array}{c}\text { Bending Angle at } \\
\mathbf{6 0 0}{ }^{\circ} \mathbf{C}\left({ }^{\circ}\right)\end{array}$ & $\begin{array}{c}\text { Bending Angle at } \\
\mathbf{7 0 0}{ }^{\circ} \mathbf{C}\left({ }^{\circ}\right)\end{array}$ & $\begin{array}{c}\text { Bending Angle at } \\
\mathbf{8 0 0}{ }^{\circ} \mathbf{C}\left({ }^{\circ}\right)\end{array}$ & $\begin{array}{c}\text { Bending Angle at } \\
\mathbf{9 0 0}{ }^{\circ} \mathbf{C}\left({ }^{\circ}\right)\end{array}$ \\
\hline $\mathrm{EPDM} / \mathrm{AF}_{0}$ & 16.32 & 67.42 & 90 & 90 \\
$\mathrm{EPDM} / \mathrm{AF}_{5}$ & 10.63 & 12.46 & 21.65 & 39.91 \\
$\mathrm{EPDM} / \mathrm{AF}_{10}$ & 0 & 0 & 5.37 & 9.6 \\
$\mathrm{EPDM} / \mathrm{AF}_{15}$ & 0 & 0 & 0 & 6.38 \\
\hline
\end{tabular}

\subsection{Linear Ablation Property of Ceramifiable EPDM Composites}

Table 8 shows the ablation rates of the ceramifiable EPDM composites after exposure to the oxyacetylene torch flame for $20 \mathrm{~s}$ under $4110.0 \mathrm{KW} / \mathrm{m}^{2}$ of heat flux. Sample EPDM/AF $\mathrm{E}_{0}$ was burned through, as shown in Figure S3 (Supplementary Materials). However, the linear ablation rate of composites decreased from $0.28 \mathrm{~mm} / \mathrm{s}$ to $0.23 \mathrm{~mm} / \mathrm{s}$ when the AF content in the samples increased from 5 to $15 \mathrm{wt} \%$, and their back sides maintained the original features. This indicated that the introduction of AF greatly improved the ablation performance [42].

Table 8. Linear ablation rate of ceramifiable EPDM composites.

\begin{tabular}{cc}
\hline Sample & Linear Ablation Rate $(\mathbf{m m} / \mathbf{s})$ \\
\hline${\text { EPDM } / \mathrm{AF}_{0}}_{\mathrm{EPDM} \mathrm{AF}_{5}}$ & ${ }^{\mathrm{a}}$ \\
$\mathrm{EPDM} / \mathrm{AF}_{10}$ & 0.28 \\
$\mathrm{EPDM} / \mathrm{AF}_{15}$ & 0.25 \\
\multicolumn{2}{c}{${ }^{\mathrm{a}}$ Sample was burned through. }
\end{tabular}

\subsection{Flexural Strength and Linear Shrinkage of Ceramifiable EPDM Composites}

Figures 4 and 5 present the effects of AF on the flexural strength and linear shrinkage of the ceramifiable EPDM composites fired at different temperatures. In the temperature range of $700-900{ }^{\circ} \mathrm{C}$, the flexural strength of all samples increased as the firing temperature increased. This phenomenon was in accordance with the ceramifiable EVA composites [43]. It was noteworthy that the flexural strength improved as the AF content increased in $\mathrm{EPDM} / \mathrm{AF}_{5}, \mathrm{EPDM} \mathrm{AF}_{10}$, and EPDM/AF 15 under 
the same pyrolysis conditions. At $900{ }^{\circ} \mathrm{C}$, the flexural strength of the ceramic residue reached the maximum value of $10.88 \mathrm{MPa}$, exhibiting excellent mechanical properties.

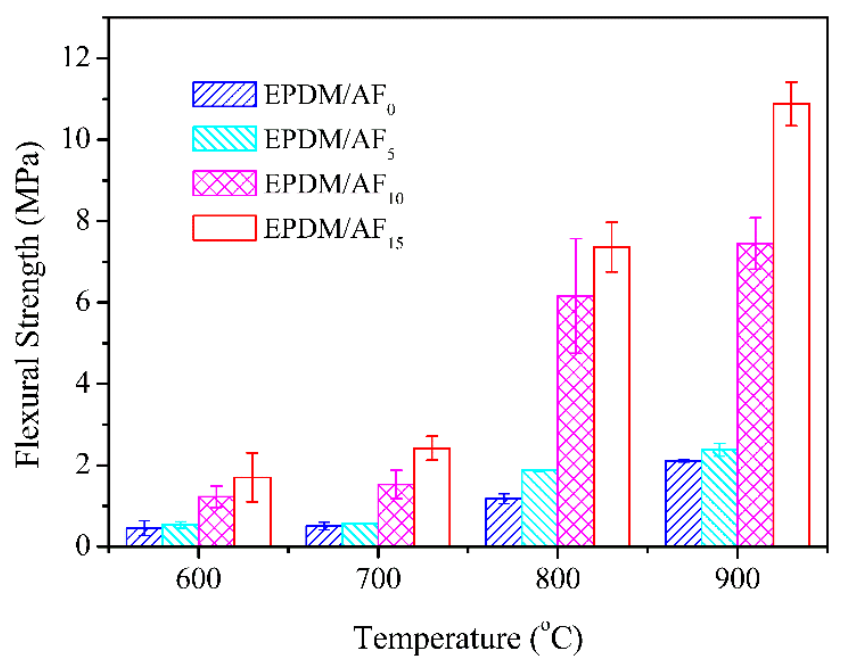

Figure 4. Flexural strength of ceramifiable EPDM composites at different temperatures.

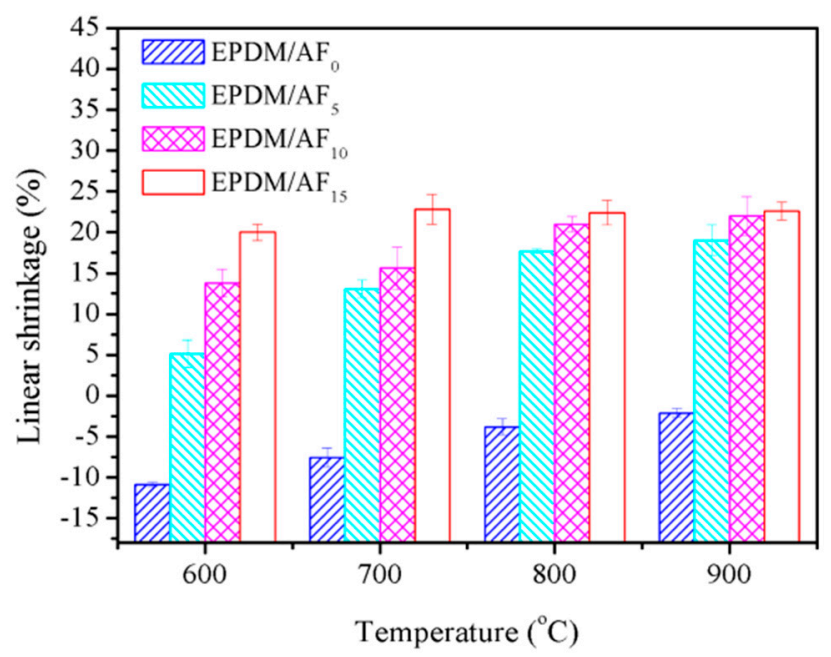

Figure 5. Linear shrinkage of ceramifiable EPDM composites at different temperatures.

$\mathrm{EPDM} / \mathrm{AF}_{0}$ exhibited linear expansion at various temperatures owing to the fast decomposition of the EPDM matrix and APP, which resulted in poor flexural strength. In the case of EPDM/AF, $\mathrm{EPDM} / 10$, and $\mathrm{EPDM} / 15$, the linear shrinkage was positive at various temperatures, indicating that a degree of sintering occurred in these samples. The linear shrinkage of the sample under the same firing conditions increased with increasing AF. In addition, taking samples EPDM/AF $\mathrm{F}_{0}$ and $\mathrm{EPDM} / \mathrm{AF}_{10}$ as examples, their surface morphology fired at 600, 700, 800, and $900^{\circ} \mathrm{C}$ is shown in Figure S1 (Supplementary Materials). These results indicated that the addition of AF can improve the compactness of the residue. These results correspond with the flexural strength results.

\subsection{Thermogravimetric Analysis}

TGA data of the samples under $\mathrm{N}_{2}$ atmosphere are presented in Figure 6 and Table 9. A characteristic temperature was used to evaluate the thermal stability: $T_{5 \%}$ (temperature when weight loss reaches $5 \mathrm{wt} \%$ ). For pure $\mathrm{AF}$, it can be seen that the $T_{5 \%}$ is $481.23{ }^{\circ} \mathrm{C}$, and the residual mass at $500{ }^{\circ} \mathrm{C}$ was $94.49 \mathrm{wt} \%$. It was possible to contribute to an excellent self-supporting performance of EPDM/AF composites at high temperatures. In addition, it could be seen that the thermal degradation of 
$\mathrm{EPDM} / \mathrm{AF}_{0}$ and $\mathrm{EPDM} / \mathrm{AF}_{10}$ both involved two main steps. There was a slight difference in the first steps of degradation between $\mathrm{EPDM} / \mathrm{AF}_{0}$ and $\mathrm{EPDM} / \mathrm{AF}_{10}$. $\mathrm{EPDM} / \mathrm{AF}_{10}$ exhibited a higher $T_{5 \%}$ degradation temperature $\left(T_{5} \% 378.39^{\circ} \mathrm{C}\right)$, while $\mathrm{EPDM} / \mathrm{AF}_{0}$ displayed a lower $T_{5 \%}$ degradation temperature $\left(\mathrm{T}_{5 \%} 360.73{ }^{\circ} \mathrm{C}\right)$. For $\mathrm{EPDM} / \mathrm{AF}_{0}$, the temperature at the maximum weight loss rate $\left(T_{\max 1}\right)$ in the main step was $381.57^{\circ} \mathrm{C}$, which was lower than the corresponding value of $\mathrm{EPDM} / \mathrm{AF}_{10}\left(T_{\max 1}\right.$ $394.16^{\circ} \mathrm{C}$ ). Compared with $\mathrm{EPDM} / \mathrm{AF}_{0}$, the char residue of $\mathrm{EPDM} / \mathrm{AF}_{10}$ increased from $56.74 \%$ to $57.62 \%$ at $500{ }^{\circ} \mathrm{C}$. The occurrence of these behaviors could be attributed to the existence of the AF network structure, resulting in a higher thermal stability of the EPDM/AF system [44]. In addition, a weak thermal degradation step appeared between $550-600{ }^{\circ} \mathrm{C}$ owing to the slower pyrolysis of AF. This indicated that AF can still remain after the pyrolysis of EPDM and APP. Therefore, the addition of AF not only can improve the thermal stability of the sample before the formation of crystalline phases but also can increase the compactness of the residue.
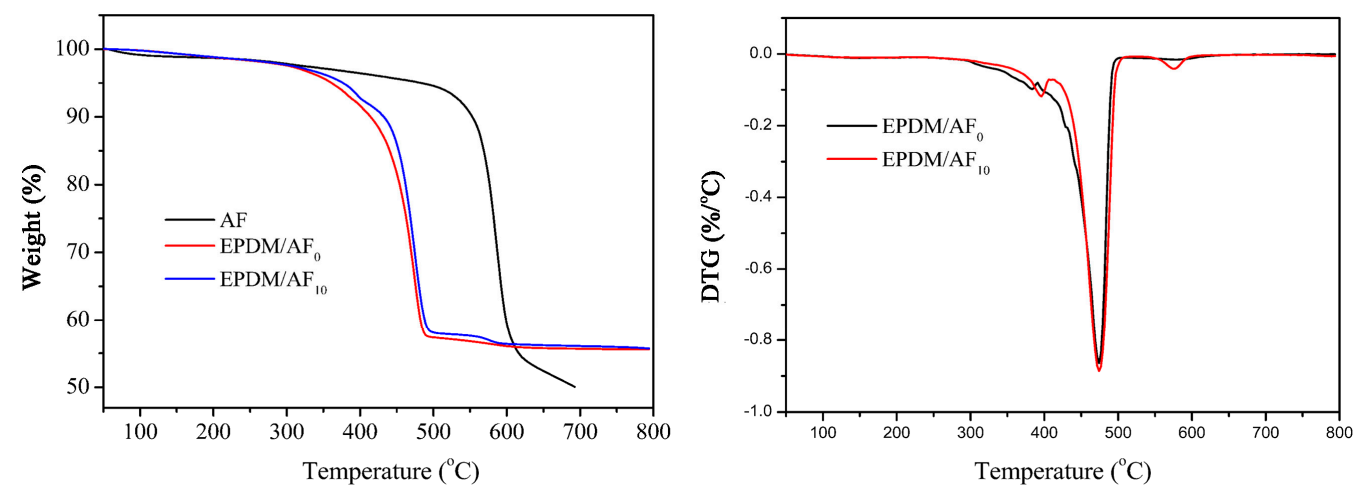

Figure 6. Thermogravimetry (TG) and differential thermogravimetry (DTG) curves of samples AF, $\mathrm{EPDM} / \mathrm{AF}_{0}$ and $\mathrm{EPDM} / \mathrm{AF}_{10}$ under $\mathrm{N}_{2}$.

Table 9. TGA data of AF, EPDM/AF 0 and $E P D M / A F_{10}$ under $\mathrm{N}_{2}$.

\begin{tabular}{cccc}
\hline Sample & $\boldsymbol{T}_{\mathbf{5 \%}}\left({ }^{\circ} \mathbf{C}\right)$ & $\boldsymbol{T}_{\boldsymbol{m a x} \mathbf{1}}\left({ }^{\circ} \mathbf{C}\right)$ & Residue at $\mathbf{5 0 0}{ }^{\circ} \mathbf{C}(\mathbf{w t} \mathbf{\%})$ \\
\hline AF & 481.23 & - & 94.49 \\
EPDM/AF0 & 360.73 & 381.57 & 56.74 \\
EPDM/AF10 & 378.39 & 394.16 & 57.62 \\
\hline
\end{tabular}

\subsection{SEM Analysis}

Figure 7 shows the SEM images of the sample EPDM/AF 10 fired at $350{ }^{\circ} \mathrm{C}$ for $20 \mathrm{~min}$. It clearly shows the existent form of AF in the cross section of residue, and the structure of AF is relatively undamaged. In addition, residues from SGF, APP, and EPDM decomposition attached to the fiber. Thus, anti-dripping and self-supporting properties of ceramifiable EPDM composites were improved owing to the increase in interaction between residues at high temperatures.

The surface structures of the residues of $\mathrm{EPDM} / \mathrm{AF}_{0}$ fired at $600{ }^{\circ} \mathrm{C}$ and $800{ }^{\circ} \mathrm{C}$ for $30 \mathrm{~min}$ are shown in Figure 8a,c. The surface of the residue fired at $600{ }^{\circ} \mathrm{C}$ exhibited many pores in Figure 8a. The formation of pores was attributed to the pyrolysis of APP and the EPDM matrix. However, when the sample fired at $800{ }^{\circ} \mathrm{C}$, a more compact structure was formed, as observed in Figure 8c. Densification of the residue can be due to the strong liquidity of molten fillers at high temperatures. Therefore, the flexural strength increased with the increase in firing temperature, and this was also consistent with previous research on the EVA system [27]. 

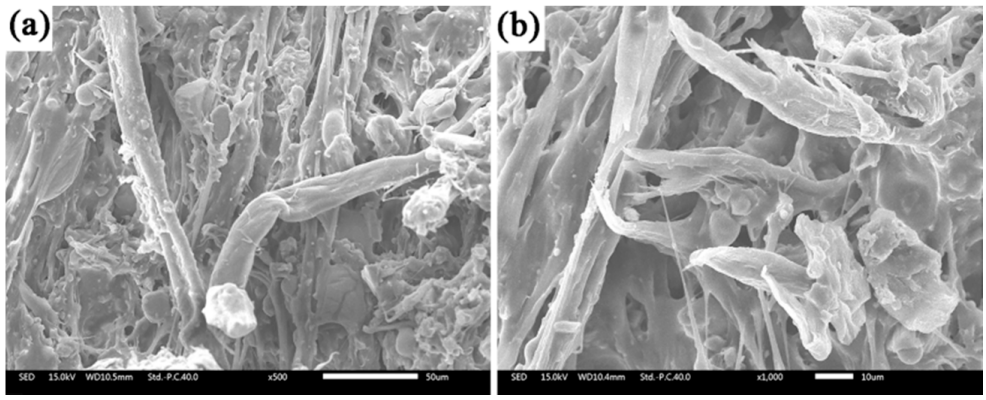

Figure 7. SEM of the sample EPDM/AF 10 fired at $350{ }^{\circ} \mathrm{C}$ for $20 \mathrm{~min}:(\mathbf{a}) \times 500 ;(\mathbf{b}) \times 1000$.
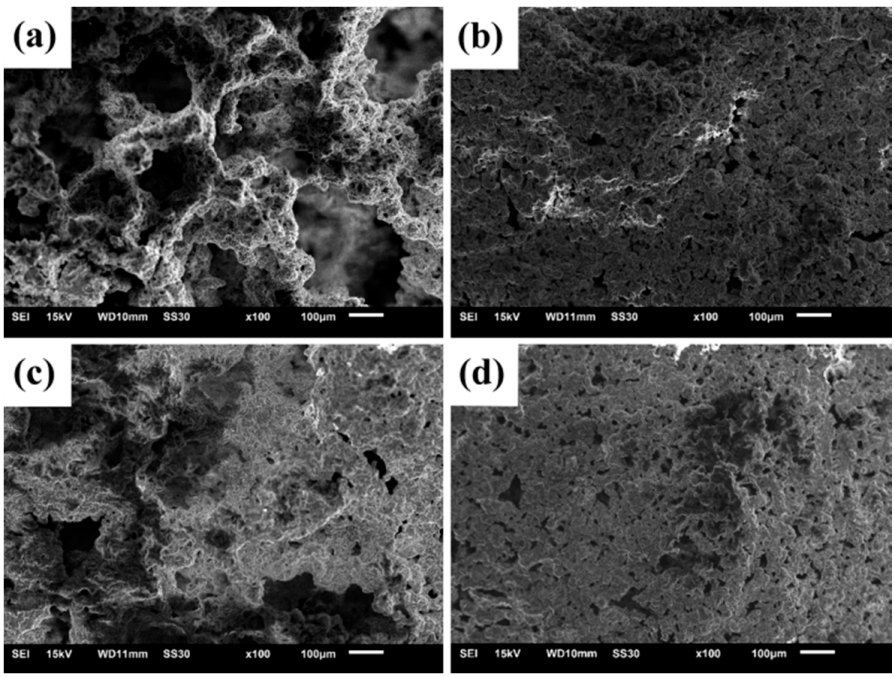

Figure 8. Surface images of samples: $\mathrm{EPDM} / \mathrm{AF}_{0}$ after firing at $600{ }^{\circ} \mathrm{C}(\mathrm{a})$ and $800{ }^{\circ} \mathrm{C}(\mathrm{c}) ; \mathrm{EPDM} / \mathrm{AF}_{10}$ after firing at $600{ }^{\circ} \mathrm{C}(\mathbf{b})$ and $800{ }^{\circ} \mathrm{C}(\mathbf{d})$.

It is noteworthy that the residues of $\mathrm{EPDM} / \mathrm{AF}_{10}$ showed a more compact structure at corresponding temperatures compared with the residues of $\mathrm{EPDM} / \mathrm{AF}_{0}$. As shown in Figure $8 \mathrm{~b}, \mathrm{~d}$, a dense microstructure was formed at 600 and $800{ }^{\circ} \mathrm{C}$, which caused the improvement in the flexural strength of the fired samples. According to the results of $\mathrm{EPDM} / \mathrm{AF}_{0}$ and $\mathrm{EPDM} / \mathrm{AF}_{10}$, a possible mechanism for the formation of the compact surface structure of the EPDM/AF 10 residue was suggested. For EPDM/AF 10 , the formation of the compact ceramic structure can be attributed to the existence of AF. During the processing of composites, the AF fibers were subjected to a degree of stretching and orientation. With the temperature increasing, AF will shrink slowly [5]. The shrinkage behavior of AF at high temperatures can be seen in Figure S2 (Supplementary Materials). Thermal shrinkage of AF will make the close-contacted fillers and EPDM matrix move together; thus, the addition of AF leads to the obvious shrinkage of ceramifiable EPDM composites at high temperatures and improves the sintering densification.

\subsection{Mechanism for the Transformation to Ceramic at High Temperature}

The existence of AF inhibited the dripping and bending of the ceramifiable EPDM composite at high temperature $\left(500-600{ }^{\circ} \mathrm{C}\right)$. Theoretically, when the firing temperature is higher than the decomposition temperature of the AF, the material will tend to bend or melt drip due to the fusibility and flow properties of inorganic fillers [24,27]. On the contrary, the EPDM/AF system still showed a good self-supporting property over $600{ }^{\circ} \mathrm{C}$.

To identify the phase composition of the residue, XRD and FTIR were performed for the residues formed at various temperatures, and the results are shown in Figures 9 and 10. It is shown that an 
obvious "hump" appeared at $15^{\circ}-35^{\circ}$, indicating the amorphous structure $[45,46]$ of $\mathrm{EPDM} / \mathrm{AF}_{10}$ after firing at $600{ }^{\circ} \mathrm{C}$. Meanwhile, there are some weak peaks appearing at the $2 \theta$ of $20.09^{\circ}$ and $21.83^{\circ}$ represented sodium phosphate (Pdf No.11-383) and cristobalite (Pdf No.1-438), respectively [23,47]. With increasing temperature, the "hump" became very weak, and even disappeared. When EPDM/AF 10 was fired at $700{ }^{\circ} \mathrm{C}$ or even higher, the main crystalline phase of its residues was cristobalite. For the FTIR curve, the peak at $1022 \mathrm{~cm}^{-1}$ is assigned to the vibration of Si-O-Si in SGF [48-50]. The absorbing peak at $3445 \mathrm{~cm}^{-1}$ is ascribed to the stretching vibration of the $\mathrm{O}-\mathrm{H}$ bond [51], which gradually decreased when the temperature increased. These changes meant a change in the SGF structure. For ceramic residues formed at $600{ }^{\circ} \mathrm{C}$ and $700{ }^{\circ} \mathrm{C}$, it was found that some new peaks appeared at $914 \mathrm{~cm}^{-1}$ and $557 \mathrm{~cm}^{-1}$, which was ascribed to the formation of the sodium phosphate [52]. Moreover, with the temperature increasing, a new peak appeared at $620 \mathrm{~cm}^{-1}$, and the peak at $792 \mathrm{~cm}^{-1}$ became stronger in the FTIR spectrum of residues of $\mathrm{EPDM} / \mathrm{AF}_{10}$, representing the formation of cristobalite [53]. These results were consistent with the analysis of $X R D$, and illustrated that the phase change occurred when the EPDM/AF 10 composite was fired at higher temperatures. Thus, the composite showed a good self-supporting property even if the firing temperature was higher than the melting point of the SGF.

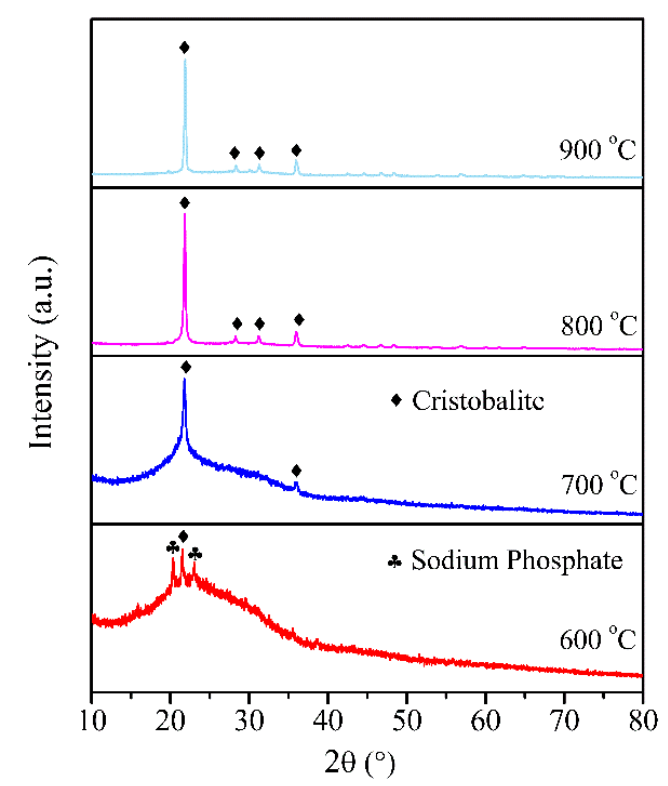

Figure 9. $\mathrm{XRD}$ patterns of residues of $\mathrm{EPDM} / \mathrm{AF}_{10}$ fired at different temperatures.

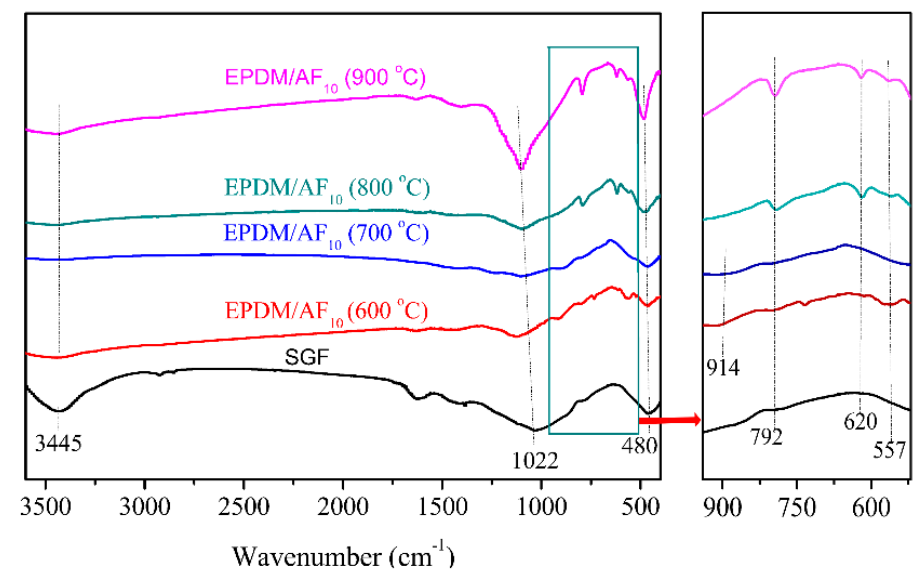

Figure 10. FTIR spectra of silicate glass frits (SGF) and residues of EPDM/AF 10 fired at different temperatures. 
The formation mechanism of this novel ceramifiable EPDM composite was proposed as shown in Figure 11. Below about $600^{\circ} \mathrm{C}$, the ceramifiable EPDM composite can support its own weight very well with the AF network structures. The formation of crystalline phases (sodium phosphate and cristobalite) played a significant role in keeping the self-supporting property of the ceramifiable EPDM composite above $600^{\circ} \mathrm{C}$.

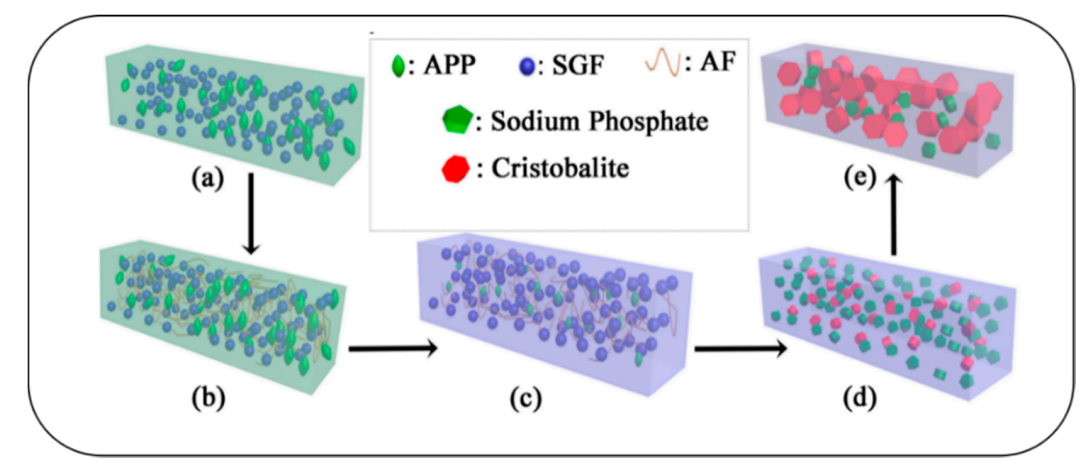

Figure 11. Schematic presentation of the mechanism of self-supporting: (a) ceramifiable EPDM composite without $\mathrm{AF}$, (b) EPDM/AF composite, (c) fired at below $600{ }^{\circ} \mathrm{C}$, (d) fired at a range of $600-800{ }^{\circ} \mathrm{C}$, and (e) fired at above $800{ }^{\circ} \mathrm{C}$.

\section{Conclusions}

A ceramifiable EPDM composite with fiber network structures was successfully prepared. AF as a "skeletal structure" existed in the ceramifiable EPDM composite system. The AF network structure reinforced the interaction between EMPD and fillers. Compared with the ceramifiable EPDM composite without $\mathrm{AF}$, the tear strength of $\mathrm{EPDM} / \mathrm{AF}_{15}$ increased from 11.53 to $22.02 \mathrm{~N} / \mathrm{m}$. The solvent resistance and ablative resistance of the ceramifiable EPDM composite with AF were also enhanced. With the addition of $\mathrm{AF}$, the ceramifiable and self-supporting properties of the ceramifiable EPDM composite were improved significantly. Compared with the residue of ceramifiable EPDM composite without AF, the residue of EPDM/AF system had higher flexural strength and a more compact structure. The excellent self-supporting property of the EPDM/AF system was obtained by combining the formation of the AF network and the formation of crystalline phases at higher temperature (above $600^{\circ} \mathrm{C}$ ). This study provides a new thought and route to prepare ceramifiable polymer composites with excellent overall performance, which will be of great theoretical and practical significance.

Supplementary Materials: The following are available online at http://www.mdpi.com/2073-4360/12/7/1523/s1, Figure S1: Photos of surface morphology of samples EPDM/AF0 (left) and EPDM/AF10 (right) fired at $600{ }^{\circ} \mathrm{C}$ (a), $700{ }^{\circ} \mathrm{C}(\mathrm{b}), 800{ }^{\circ} \mathrm{C}(\mathrm{c})$ and $900{ }^{\circ} \mathrm{C}(\mathrm{d})$; Figure S2: Digital photos of AF before and after heat reatment at $400{ }^{\circ} \mathrm{C}$; Figure S3: Photographic image of the back side and front side of the composites after ablation rate test.

Author Contributions: Investigation, D.Z. and W.L.; Methodology, D.Z., Y.S., G.J., and T.W.; Writing-original draft, D.Z.; Writing - review \& editing, D.Z. and Y.S. All authors have read and agreed to the published version of the manuscript.

Funding: This work was supported by National Natural Science Foundation of China (No. 51703096), Industry Foresight and Generic Key Technology of Suqian (H201816), China Postdoctoral Science Foundation (2018M64229), and the Priority Academic Program Development of Jiangsu Higher Education Institutions (PAPD).

Conflicts of Interest: The authors declare no conflicts of interest.

\section{References}

1. Youren, J.W. Ablation of elastomeric composites for rocket motor insulation. Composites 1971, 2, 180-184. [CrossRef]

2. Natali, M.; Torre, L. Composites materials: Ablative. In Wiley Encyclopedia of Composites; John Wiley \& Sons: New York, NY, USA, 2012. [CrossRef] 
3. Gao, G.; Zhang, Z.; Zheng, Y.; Jin, Z. Effect of fiber orientation angle on thermal degradation and ablative properties of short-fiber reinforced EPDM/NBR rubber composites. Polym. Compos. 2010, 31, 1223-1231. [CrossRef]

4. Donskoy, A.A.; Zaikov, G.E. Elastomeric heat-shielding materials for internal surfaces of missile engines. Int. J. Polym. Mater. 1995, 31, 215-236. [CrossRef]

5. Natali, N.M.; Marco, R.; Jose, K.; Luigi, T. Effect of wollastonite on the ablation resistance of EPDM based elastomeric heat shielding materials for solid rocket motors. Polym. Degrad. Stab. 2016, 130, 47-57. [CrossRef]

6. Bhuvaneswari, C.M.; Sureshkumer, M.S.; Kakade, S.D.; Gupta, M. Ethylene-propylene diene rubber as a futuristic elastomer for insulation of solid rocket motors. Def. Sci. J. 2006, 56, 309-320. [CrossRef]

7. Brydson, J.A. Rubber Chemistry; Applied Science Press: London, UK, 1978.

8. Kim, J.; Bae, J.; Lee, J.; Lee, Y.H.; Kim, H.D. Preparation and properties of high-performance recyclable ethylene propylene diene rubber. J. Appl. Polym. Sci. 2015, 132. [CrossRef]

9. Yen, Y.Y.; Wang, H.T.; Guo, W.J. Synergistic effect of aluminum hydroxide and nanoclay on flame retardancy and mechanical properties of EPDM composites. J. Appl. Polym. Sci. 2013, 130, 2042-2048. [CrossRef]

10. Kremers, A.; Krusche, A.; Haberstroh, E. Analysis of the production of sponge rubber profiles. Macromol. Mater. Eng. 2000, 284, 70-75. [CrossRef]

11. Wu, J.; Chuang, C.B.; Wang, Y.S.; Jiang, H.G.; Lu, M. Research on rensile/compression mechanical behavior of EPDM for aviation applications. China Rubber Ind. 2018, 65, 1210-1213.

12. Jaramillo, M.; Koo, J.H.; Natali, M. Compressive char strength of thermoplastic polyurethane elastomer nanocomposites. Polym. Adv. Technol. 2014, 25, 742-751. [CrossRef]

13. He, J.Y.; Hao, H.J.; Zhou, X.Y.; Yang, R.J.; Huang, F.L.; Li, J.M.; Zhang, Y.L. Investigation on ablation effects of propellant containing organic fluoride on EPDM insulation materials. J. Propuls. Technol. 2019, 40, 2350-2357. [CrossRef]

14. Martin, H.T. Assessment of the Performance of Ablative Insulators under Realistic Solid Rocket Motor Operating Conditions. Ph.D. Thesis, The Penn-Sylvania State University, State College, PA, USA, 1 May 2013.

15. Hanu, L.G.; Simon, G.P.; Mansouri, J.; Burford, R.P.; Cheng, Y.B. Development of polymer ceramic composites for improved fire resistance. J. Mater. Process. Technol. 2004, 153, 401-407. [CrossRef]

16. Alexander, G.; East, H.; Cheng, Y.B.; Burwood, E.; Burford, R.P.; Shanks, R.; Mansouri, J.; Hodzic, A.; Wood, C.; Genovese, A.; et al. Fire-Resistant Silicone Polymer Compositions. U.S. Patent 7652090, 26 January 2010.

17. Henrist, C.; Rulmont, A.; Cloots, R.; Gilbert, B.; Bernard, A.; Beyer, G. Toward the understanding of the thermal degradation of commercially available fire-resistant cable. Mater. Lett. 2000, 46, 160-168. [CrossRef]

18. Hanu, L.G.; Simon, G.P.; Cheng, Y.B. Preferential orientation of muscovite in ceramifiable silicone composites. Mater. Sci. Eng. A 2005, 398, 180-187. [CrossRef]

19. Mansouri, J.; Cheng, R.P.; Cheng, Y.B.; Burford, R.P.; Hanu, L. Formation of strong ceramified ash from silicone-based compositions. J. Mater. Sci. 2005, 40, 5741-5749. [CrossRef]

20. Bennett, J.A.; Young, R.J. The effect of fibre matrix adhesion upon crack bridging in fibre reinforced composites. Compos. Part. A Appl. 1998, 29, 1071-1081. [CrossRef]

21. Zhang, X.P.; Guan, Y.Y.; Xie, Y.; Qiu, D. "House-of-cards” structures in silicone rubber composites for superb anti-collapsing performance at medium high temperature. RSC Adv. 2016, 6, 7970-7976. [CrossRef]

22. Hamdani, S.; Longuet, C.; Perrin, D.; Lopez-cuesta, J.M.; Ganachaud, F. Flame retardancy of silicone-based materials. Polym. Degrad. Stab. 2009, 94, 465-495. [CrossRef]

23. Zhao, D.; Shen, Y.C.; Wang, T.W. Ceramifiable EVA/APP/SGF composites for improved ceramifiable properties. Polym. Degrad. Stab. 2018, 150, 140-147. [CrossRef]

24. Gong, X.H.; Wu, T.Y.; Ma, J.; Zhao, D.; Shen, Y.C.; Wang, T.W. Improved self-supporting property of ceramifying silicone rubber composites by forming crystalline phase at high temperatures. J. Alloys Compd. 2017, 706, 322-329. [CrossRef]

25. Ma, Q.; He, F.J.; Liu, H.Y.; Liu, H.; Wei, Z. Effect of cross-linking on rheological properties and a model for flexibility-rigidity transition in SBS/PBMA LIPNs. J. Polym. Eng. 2016, 36, 149-156. [CrossRef]

26. Chowdhury, S.R.; Sabhawal, S. Development of recyclable electron beam radiation crosslinked LDPE/EVA-embedded nanoclay nanocomposites. J. Reinf. Plast. Compos. 2012, 31, 1426-1434. [CrossRef]

27. Zhao, D.; Xia, M.L.; Shen, Y.C.; Wang, T.W. Three-dimensional cross-linking structures in ceramifiable EVA composites for improving self-supporting property and ceramifiable properties at high temperature. Polym. Degrad. Stab. 2019, 162, 94-101. [CrossRef] 
28. Hearle, J.W.S. High-Performance Fibres; CRC Press: Boca Raton, UK, 2001.

29. Ahmed, A.F.; Hoa, S.V. Thermal insulation by heat resistant polymers for solid rocket motor insulation. J. Compos. Mater. 2012, 46, 1549-1559. [CrossRef]

30. Deuri, A.S.; Bhowmick, A.K.; Ghosh, R.; John, B.; Sriram, T.; De, S.K. Thermal and ablative properties of rocket insulator compound based on EPDM. Polym. Degrad. Stab. 1988, 21, 21-28. [CrossRef]

31. Allred, L.D.; Eddy, N.F. Asbestos Free Insulation Development for the Space Shuttle Solid Propellant Rocket Motor (RSRM); Thiokol Press: Brigham, UT, USA, 2000.

32. Zou, Z.Y.; Qin, Y.; Liu, L.D.; Huang, Z.X. Effect of the flux on the fire-resistance properties of ceramifiable EPDM rubber composites. Adv. Compos. Lett. 2018, 27, 89-95. [CrossRef]

33. Chen, S.; Wu, W.D.; Chen, Y.B.; Xiang, N.; Zhou, Y.J.; Tang, N.; Wu, J.G.; Sun, Y.B.; Sa, R.N. Modification research of application of predispersed aramid pulp masterbatch to conveyor belts. Spec. Purp. Rubber. Prod. 2017, 38, 7-11.

34. Maurizio, N.; Marco, R.; Debora, P.; Josè, K.; Torre, L. EPDM based heat shielding materials for solid rocket motors: A comparative study of different fibrous reinforcements. Polym. Degrad. Stab. 2013, 98, 2131-2139. [CrossRef]

35. Li, J.; Liu, K.; Guo, M.F.; Liu, Y.; Wang, J.; Lv, X. Ablation and erosion characteristics of EPDM composites under SRM operating conditions. Compos. Part A Appl. Sci. Manuf. 2018, 109, 392-401. [CrossRef]

36. Zirnstein, B.; Schulze, D.; Schartel, B. The impact of polyaniline in phosphorus flame retardant ethylene-propylene-diene-rubber (EPDM). Thermochim. Acta 2019, 673, 92-104. [CrossRef]

37. Zhu, S.S.; Zhang, W.X.; Zhang, J. High dielectric acrylonitrile-butadiene rubber with excellent mechanical properties by filling with surface-modified barium/strontium inorganic functional powders. J. Mater. Sci. 2018, 29, 6519-6529. [CrossRef]

38. Li, P.; Luo, Z.; Zhong, J.H.; Zhou, Z.T.; Liu, C.L. Influence of impregnating latex pretreatment of short amid fibers on properties of filled EPDM rubber material. Polym. Mater. Sci. Eng. 2019, 35, 41-46.

39. Saeoui, P.; Sirisinha, C.; Thepsuwan, U.; Thapthong, P. Influence of accelerator type on properties of NR/EPDM blends. Polym. Test. 2007, 26, 1062-1067. [CrossRef]

40. Alakrach, A.M.; Noriman, N.Z.; Alrawi, L.I.; Dahham, O.S.; Latip, N.A.; Hakim, I.L.; Johari, I. Cure characteristics and physical properties of SMR L/EPDM blends: Effects of blend ratios. IOP Conf. Ser. Mater. Sci. Eng. 2018, 454. [CrossRef]

41. Sam, S.T.; Dahham, O.S.; Gan, P.G.; Noimam, N.Z.; Kuan, J.Y.; Alakrach, A.M. Studies on tensile properties of compatibilized and uncompatibilized low-density polyethylene/jackfruit seed flour (LDPE/JFSF) blends at different JFSF content. Solid State Phenom. 2017, 264, 120-123. [CrossRef]

42. Zhao, X.; Wang, Y.G.; Duan, L.Y.; Luo, L.; Lu, Y.H. Improved ablation resistance of C/SiC-ZrB 2 composites via polymer precursor impregnation and pyrolysis. Ceram. Int. 2017, 43, 12480-12489. [CrossRef]

43. Lou, F.P.; Wu, K.; Wang, Q.; Qian, Z.Y.; Li, S.J.; Guo, W.D. Improved flame-retardant and ceramifiable properties of EVA composites by combination of ammonium polyphosphate and aluminum hydroxide. Polymers 2019, 11, 125. [CrossRef]

44. Zhu, X.J.; Zhang, S.; Zhang, G.H.; Yang, W.M.; Wu, W.D. Effect of flame retardant and aramid pulpon the properties of EPDM. Spec. Purp. Rubber. Prod. 2010, 31, 16-23.

45. Mansouri, J.; Burford, R.P.; Cheng, Y.B. Pyrolysis behaviour of silicone-based ceramifying composites. Mater. Sci. Eng. A Struct. Mater. Proper. Microstruct. Process. 2006, 425, 7-14. [CrossRef]

46. Guo, H.; Gao, W.; Wang, Y.; Liang, D.; Li, H.; Zhang, X. Effect of glass frit with low softening temperature on the properties, microstructure and formation mechanism of polysiloxane elastomer-based ceramizable composites. Polym. Degrad. Stab. 2017, 136, 71-79. [CrossRef]

47. Honma, T.; Sato, A.; Takuya, N.I.; Togashi, T.; Shinozaki, K.; Komatsu, T. Crystallization behavior of sodium iron phosphate glass $\mathrm{Na}_{2}-\mathrm{x} \mathrm{Fe}_{1}+0.5_{\mathrm{x}} \mathrm{P}_{2} \mathrm{O}_{7}$ for sodium ion batteries. J. Non-Cryst. Solids 2014, 404, $26-31$. [CrossRef]

48. Yu, L.; Xiao, H.; Cheng, Y. Influence of magnesia on the structure and properties of $\mathrm{MgO}^{-} \mathrm{Al}_{2} \mathrm{O}_{3}-\mathrm{SiO}_{2}-\mathrm{FA}$ glass-ceramics. Ceram. Int. 2008, 34, 63-68. [CrossRef]

49. Roy, S.; Basu, B. On the development of two characteristically different crystal morphology in $\mathrm{SiO}_{2}-\mathrm{MgO}-\mathrm{Al}_{2} \mathrm{O}_{3}-\mathrm{K}_{2} \mathrm{O}-\mathrm{B}_{2} \mathrm{O}_{3}-\mathrm{F}$ glass-ceramic system. J. Mater. Sci. Mater. Med. 2008, 20, 51-66. [CrossRef] [PubMed] 
50. Molla, A.R.; Basu, B. Microstructure, mechanical, and in vitro properties of micaglass-ceramics with varying fluorine content. J. Mater. Sci. 2008, 20, 869-882. [CrossRef]

51. Li, Y.M.; Deng, C.; Wang, Y.Z. A novel high-temperature-resistant polymeric material for cables and insulated wires via the ceramization of mica-based ceramifiable EVA composites. Compos. Sci. Technol. 2016, 132, 116-122. [CrossRef]

52. Sascha, C.C.; Marcel, S. Complex nucleation and crystal growth mechanisms in applied multi component glass-ceramics. Glastech. Ber. Glass. Sci. Technol. 2000, 73, 12-19.

53. Chen, H.S.; Ji, S.F.; Niu, J.Z.; Xie, B.H.; Li, S.B. Vibration spectroscopy on transformation of amorphous silica to cristobalite. Acta Phys. Chim. 1999, 15, 454-457.

(C) 2020 by the authors. Licensee MDPI, Basel, Switzerland. This article is an open access article distributed under the terms and conditions of the Creative Commons Attribution (CC BY) license (http://creativecommons.org/licenses/by/4.0/). 